\title{
A família Cactaceae no Parque Nacional de Boa Nova, Estado da Bahia, Brasil
}

\author{
Silvana dos Santos Simões ${ }^{1}$, (1) Daniela C. Zappi² e (i) Lidyanne Yuriko Saleme Aona ${ }^{1,3}$
}

Recebido: 17.12.2019; aceito: 17.07.2020

Como citar: Simões, S.S., Zappi, D.C. \& Aona, L.Y.S. 2020. A família Cactaceae no Parque Nacional de Boa Nova, Estado da Bahia, Brasil. Hoehnea 47: e1102019. http://dx.doi.org/10.1590/2236-8906-110/2019.

RESUMO - (A família Cactaceae no Parque Nacional de Boa Nova, Estado da Bahia, Brasil). A família Cactaceae inclui 1.850 espécies distribuídas primariamente no continente americano, sendo o Brasil o terceiro maior centro de diversidade da família, com 277 espécies. Neste último centro de diversidade, o Parque Nacional de Boa Nova (PNBN), localizado no leste do Estado da Bahia, Brasil, possui uma área com cerca de 12.065 ha, incluindo um ecótono sentido leste-oeste, com áreas de Mata Atlântica sendo substituídas por mata-de-cipó e, mais a oeste, pela Caatinga. Como parte da proposta do Plano de Ação Nacional para conservação das Cactáceas de 2011, este trabalho apresenta o estudo taxonômico de Cactaceae ocorrentes no PNBN, e tem como objetivo ampliar o conhecimento da flora local e das Unidades de Conservação do Estado da Bahia. O material foi coletado em quatro expedições de coleta durante um ano, em trilhas aleatórias percorrendo os diversos ambientes do parque. Foram registrados 10 gêneros e 15 espécies: Arrojadoa penicillata, Brasilicereus phaeacanthus, Brasiliopuntia brasiliensis, Cereus jamacaru, Cereus sp., Melocactus ernestii, Pereskia aculeata, P. bahiensis, Pilosocereus catingicola, P. pentaedrophorus subsp. robustus, Rhipsalis hileiabaiana, R. russellii, Stephanocereus leucostele, Tacinga funalis e $T$. werneri. No âmbito do PNBN, as vegetações de mata-de-cipó e Caatinga foram as que apresentaram o maior número de espécies, com oito e cinco espécies, respectivamente, enquanto a Mata Atlântica apresentou uma única espécie.

Palavras-chave: Caatinga, florística, Mata Atlântica, Unidade de Conservação

ABSTRACT - (The Cactaceae in the Parque Nacional de Boa Nova, Bahia State, Brazil). Comprising 1,850 accepted species, the Cactaceae are distributed primarily in the Americas. Brazil is the third largest diversity center for the family, with 277 species. Within this last center, the Parque Nacional de Boa Nova (PNBN), in eastern Bahia State, occupies an area of 12,065 ha. The vegetation of the PNBN includes a west-east ecotone where the Mata Atlântica is replaced by matade-cipó and, futher to the west, by Caatinga. As part of the Cactaceae Action plan of 2011, this work presents a taxonomic account of the Cactaceae found in the PNBN, aiming to expand the knowledge of the local flora of this area. Four collecting trips were carried out and the material was collected in random tracks throughout one year in different environments of the Park. Ten genera and 15 species were recorded: Arrojadoa penicillata, Brasilicereus phaeacanthus, Brasiliopuntia brasiliensis, Cereus jamacaru, Cereus sp., Melocactus ernestii, Pereskia aculeata, P. bahiensis, Pilosocereus catingicola, P. pentaedrophorus ssp. robustus, Rhipsalis hileiabaiana, R. russellii, Stephanocereus leucostele, Tacinga funalis and $T$. werneri. Among the different vegetation types found in the PNBN, the mata-de-cipó and the Caatinga had a higher number of species, with eight and five species respectively, while the Mata Atlântica had a single species.

Keywords: Atlantic Rainforest, Caatinga, Conservation Unit, floristic study

1. Universidade Federal do Recôncavo da Bahia, Centro de Ciências Agrárias, Ambientais e Biológicas, Rua Rui Barbosa, 710, Centro, 44380-000 Cruz das Almas, BA, Brasil

2. Universidade de Brasília, Instituto de Ciências Biológicas, Programa de Pós-Graduação em Botânica, Campus Universitário Darcy Ribeiro, Quadras 606-607, Asa Norte, 70910-900 Brasília, DF, Brasil

3. Autor para correspondência: lidyanne.aona@gmail.com 


\section{Introdução}

Distribuída primariamente no continente americano, a família Cactaceae possui apenas uma espécie no velho mundo (Rhipsalis baccifera (J.M.Muell.) Stearn), com cerca de 100 gêneros e 1.850 espécies (Hunt et al. 2006, Nyffeler \& Eggli, 2010). Os principais centros de diversidade da família encontram-se nos desertos mexicanos, na parte central dos Andes (Argentina e Bolívia) e no leste do Brasil (Minas Gerais e Bahia) (Hunt et al. 2006, Taylor \& Zappi 2004). Hernández-Hernández et al. (2014), a partir de estudos moleculares, apontam que a família tem origem sul-americana, a região norte central dos Andes do Chile, noroeste da Argentina, Bolívia e Peru, com uma concentração de gêneros diversos nesse centro de endemismo, o que reforça essa teoria. O Brasil é o terceiro maior centro de diversidade da família Cactaceae, totalizando 277 espécies, das quais 200 espécies são endêmicas (Zappi \& Taylor 2020).

No Brasil, o primeiro estudo taxonômico sobre Cactaceae foi elaborado por Schumann (1890) na Flora brasiliensis, inventariando 13 gêneros e 131 espécies nativas e exóticas. Diversos trabalhos incluindo Cactaceae brasileiras, como Britton \& Rose (1919-1923), Ritter (1979) e Hunt et al. (2006) levaram a um acréscimo do número de gêneros e espécies, mas não houve estudos de síntese acessíveis e organizados até pouco mais de um século depois, quando Taylor \& Zappi (2004) apresentaram um estudo abrangente sobre as espécies de Cactaceae do Brasil registradas nos domínios da Caatinga e boa parte da Mata Atlântica e Cerrado.

O Brasil apresenta 39 gêneros, sendo 14 gêneros endêmicos (Zappi \& Taylor 2019), apresentando uma elevada taxa de endemismo. Ainda em relação ao Brasil, os gêneros mais ricos em espécies são Rhipsalis Gaertn. (37 spp.), Pilosocereus Byles \& Rowley (29 spp.), Parodia Speg. (27 spp.) e Melocactus Link \& Otto (24 spp.) (Zappi $\&$ Taylor 2020), exibindo alto nível de singularidade que em termos de gêneros e espécies endêmicas com relação às Américas. A região Sudeste do Brasil apresenta 140 espécies e 30 gêneros, sendo Minas Gerais o Estado com a maior riqueza de espécies para o Brasil com 109 espécies catalogadas (Zappi \& Taylor 2020), seguida do Estado da Bahia com 105 espécies e 26 gêneros (Zappi \& Taylor 2020).

Como parte de uma das ações do Plano de Ação Nacional para conservação das Cactáceas - PAN Cactáceas (RibeiroSilva et al. 2011) de inventariar as espécies ameaçadas dentro de Unidades de Proteção integral da Bahia para subsidiar o manejo das unidades, este estudo tem como finalidade descrever as espécies de Cactaceae ocorrentes no PNBN, uma Unidade de Conservação designada recentemente no leste do Estado da Bahia. Desde o início dessa ação do PAN Cactáceas, já foram realizados estudos de Cactaceae no Parque Nacional do Itatiaia (RJ, Vasconcelos et al. 2017), Floresta Nacional Contendas do Sincorá (BA, Ribeiro et al. 2016), Parque Estadual da Serra da Tiririca (RJ, Gonzaga et al. 2019), Reserva Biológica do Alto da Serra de Paranapiacaba (SP, Mendes \& Sebastiani 2012), Parque
Estadual do Ibitipoca (MG, Gonzaga et al. 2014a); além de outras áreas pertinentes, como Serra dos Carajás no Pará (Zappi \& Taylor 2017), Serra Negra em Minas Gerais (Gonzaga et al. 2014b). Levantamentos florísticos de âmbito estadual existem para os Estados do Ceará (Menezes et al. 2013), Mato Grosso do Sul (Zappi et al. 2018), Paraná (Soller et al. 2014), Rio Grande do Sul (Carneiro et al. 2016), São Paulo (Zappi et al. 2007) e Sergipe (Meiado et al. 2015).

Descrições, chaves de identificação e um guia ilustrativo buscam contribuir para a identificação e conhecimento das espécies ocorrentes no PNBN. Além disso, dados sobre distribuição, período de floração e frutificação e caracteres diagnósticos de sete espécies são discutidos, além da utilização da morfologia das sementes para a identificação das espécies.

\section{Material e Métodos}

O Parque Nacional de Boa Nova (PNBN) foi criado em 2010, com o objetivo de proteger e regenerar os ecossistemas naturais encontrados na transição entre os Domínios Fitogeográficos da Floresta Atlântica e da Caatinga, em especial a Floresta Estacional Decidual (conhecido também como Mata de Cipó ou Agreste), garantindo assim a manutenção especialmente de populações de aves e mamíferos com ameaça de extinção e ainda recuperar e manter mananciais e cursos d'água, além de possibilitar o desenvolvimento de pesquisa científica (Decreto $\mathrm{s} / \mathrm{n}$ de 11/06/2010). Dotada de topografia irregular, esta área está localizada na zona de transição entre dois domínios fitogeográficos, sendo muito diversa em termos de formações vegetais e inúmeras espécies endêmicas (Birdlife, 2003). Apesar de todas essas características favoráveis para a conservação, o PNBN continua sofrendo constantes impactos de desmatamento, fogo, extração de madeira e distúrbios causados pelo pastoreio de gado (MMA 2006).

O PNBN, localizado no município de Boa Nova, Estado da Bahia, Brasil, está inserido na bacia do Rio Gongogi, afluente do rio de Contas e possui como rios principais o rio Tarugo, o rio das Mulheres, rio Uruba e rio Valentim, com temperatura média anual de $21^{\circ} \mathrm{C}$ e a precipitação pluviométrica variando desde $300 \mathrm{~mm} /$ ano na região da Caatinga até $1.500 \mathrm{~mm} /$ ano na porção da floresta úmida (Birdlife 2003). Há três tipos de variação climática no município, quente e úmido sem uma estação seca, na encosta oeste onde encontramos florestas, com temperaturas médias de $23{ }^{\circ} \mathrm{C}$ e precipitação de $1.500 \mathrm{~mm} / \mathrm{ano}$; quente e úmido com uma estação seca no inverno, na parte mais alta do município, com temperaturas médias de $20^{\circ} \mathrm{C}$ e precipitação de $1.000 \mathrm{~mm} / \mathrm{ano}$; semiárido na encosta oeste, com vegetação de Caatinga e temperaturas médias de $26^{\circ} \mathrm{C}$ e precipitação abaixo de $700 \mathrm{~mm} /$ ano. Sendo que esta transição ocorre em menos de $30 \mathrm{Km}$, de leste para oeste. O PNBN ocupa uma área de cerca de 12.065 ha e está estrategicamente disposto em uma área de transição entre os domínios da Mata Atlântica e da Caatinga, incluindo também a fitofisionomia de matade-cipó (também conhecida como agreste) (figura 1). 


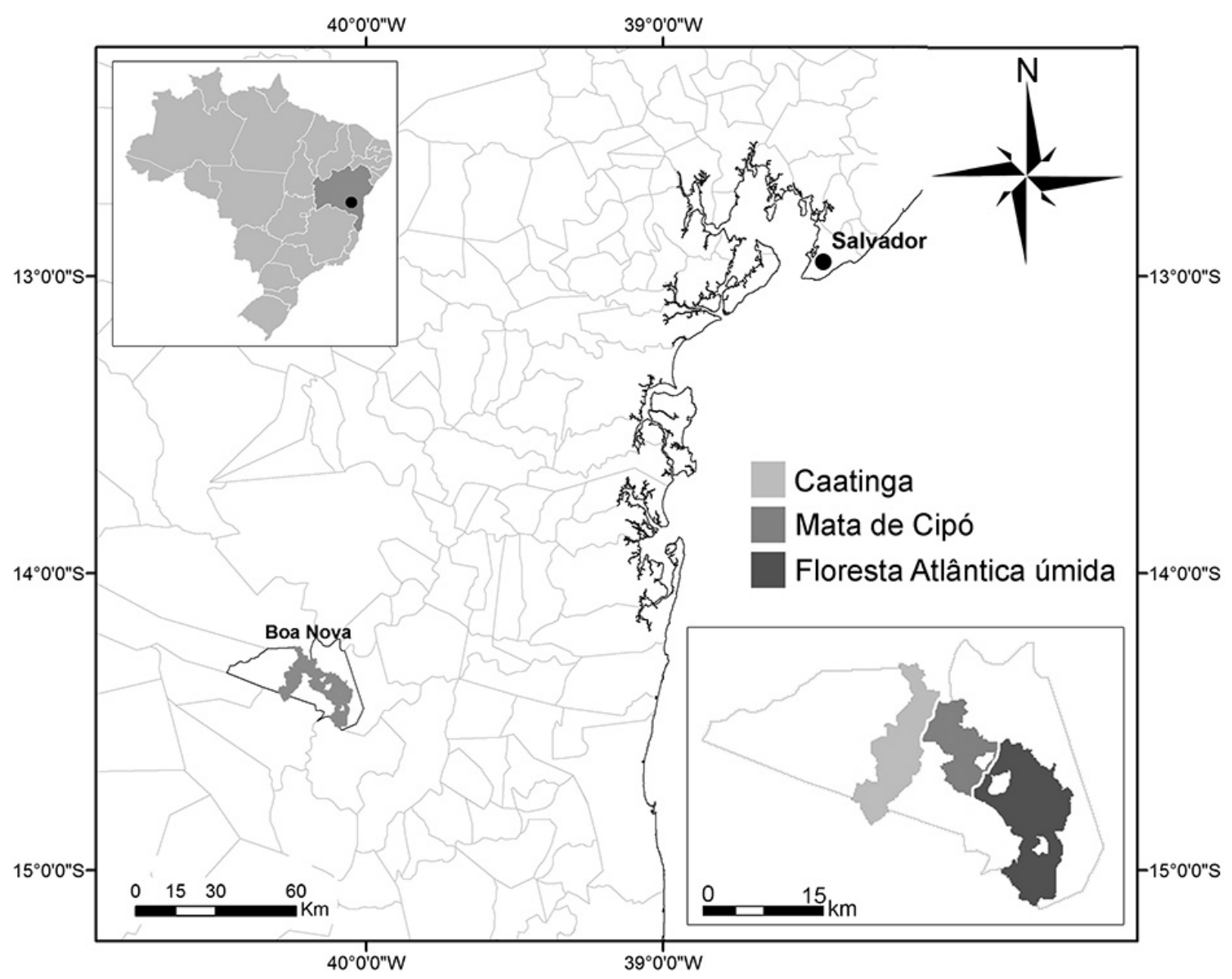

Figura 1. Mapa do Parque Nacional de Boa Nova, Estado da Bahia, Brasil, com destaque para as transições entre Caatinga, Mata de Cipó e Mata Atlântica.

Figure 1. Map of the Parque Nacional de Boa Nova, Bahia State, Brazil, highlighting the transition between Caatinga, Mata de Cipó and Atlantic Forest.

O levantamento das espécies foi feito por meio de coletas realizadas entre outubro de 2012 a novembro de 2013, a cada três meses, aproximadamente, nos diferentes tipos de vegetação. Cada expedição durou cerca de 10 dias de trabalho de campo. Foi realizado um censo visual do número de indivíduos por espécie. Material fértil foi coletado ao longo de trilhas do PNBN, sendo herborizado conforme Zappi (1994). Partes reprodutivas foram fixadas em álcool $70 \%$ para posterior estudo, mas material estéril também foi coletado. Para caracteres morfológicos não coletados ou em estado imaturo, foram inseridas informações de literatura nas descrições. Após estes procedimentos o material foi incorporado à coleção do Herbário do Recôncavo da Bahia (HURB). A caracterização morfológica das espécies foi realizada com base em plantas obtidas durante o trabalho de campo, como coloração, cor das flores e frutos e as descrições foram complementadas por estudo de coleções de Cactaceae dos acervos dos herbários ALCB, HUEFS, HURB, K, RB e SPF (acrônimo de acordo com Thiers ([2009, continuamente atualizado]). Também foram realizadas consultas às plataformas online, tais como, Reflora (reflora.jbrj.gov.br/) e o SpeciesLink (splink.cria. org.br/), a fim de encontrar outros espécimes coletados na região de estudo. As amostras foram medidas secas, como as peças florais e frutos com auxílio de um paquímetro e estereomicroscópio com câmera digital acoplada (ZEISS STEMI 2000). O material foi fixado em álcool $70 \%$ após as medições. A autorização de coleta foi emitida pelo Sistema de Autorização e Informação da Biodiversidade (SISBIO: no 35347-6).

\section{Resultados e Discussão}

A partir do trabalho de campo, foi possível identificar no PNBN 15 espécies pertencentes a 10 gêneros de Cactaceae. As vegetações de Caatinga e Floresta Estacional Semidecidual foram as que apresentaram o maior número de espécies. As Florestas Estacionais são caracterizadas como uma vegetação de transição entre a Floresta Atlântica e a Caatinga e ocupam uma estreita faixa entre esses dois 
domínios (Veloso et al. 1991, Rizzini et al. 1988). Assim como a Caatinga, as Florestas Estacionais tiveram uma redução brusca devido à expansão pecuária e agrícola, além da exploração madeireira pra utilização industrial do carvão (Baptista-Maria et al. 2009). Esse estudo ressalta a importância desse tipo de vegetação para as espécies de Cactaceae presentes na Bahia. Somente Rhipsalis hileiabaiana (N.P.Taylor \& Barthlott) N. Korotkova \& Barthlott foi coletada em Mata Atlântica no PNBN.

Vale ressaltar que a partir de expedições de campo, já foram descritas espécies endêmicas de outras famílias, como Myrcia alatiramea Sobral \& E. Lucas (Sobral et al. 2015) e Psidium rotundidiscum Proença \& Tuler (Myrtaceae), Physeterostemon gomesii Amorim \& R. Goldenb. (Melastomataceae) (Amorim et al. 2014), Pouzolzia saxophila Friis, Wilmot-Dear \& A.K.Monro (Urticaceae), ressaltando a importância desta área e de estudos de levantamentos florísticos. O PNBN também apresenta trabalhos de levantamento com as famílias Orchidaceae que possue 42 espécies (Rêgo \& Azevedo 2016) e Rubiaceae com 60 espécies (Fonseca, no prelo).

Meiado et al. (2017) revelaram que nos últimos 50 anos, pouco se tem publicado sobre sementes de Cactaceae nos diversos ecossistemas brasileiros e pesquisas envolvendo morfologia de sementes de Cactaceae são consideradas extremamente recentes no país. Segundo Barthlott \& Hunt (2000), alguns caracteres nas sementes são importantes na delimitação das espécies, como a coloração e a presença de depressões na testa, por exemplo. A coloração da semente depende da espessura e pigmentação da testa, mas também pode ser influenciada pela escultura da superfície celular (Barthlott \& Hunt 2000). Apesar das características morfológicas das sementes das espécies aqui estudadas auxiliarem na sua delimitação, somente as de sete espécies puderam ser investigadas. . No trabalho de Meiado et al. (2017) são citados estudos sobre morfologia de sementes, porém nenhum deles incluem as espécies que não foram contempladas em nosso estudo. Dessa forma, recomenda-se que se realize esse tipo de estudo para os futuros trabalhos de levantamento taxonômico da família.

Como parte dos resultados desse trabalho, também foi elaborado um guia de campo (https://fieldguides. fieldmuseum.org/sites/default/files/rapid-color-guidespdfs/727_brazil_cactcaeae_de_boa_nova.pdf) contendo outras ilustrações das espécies ocorrentes no local estudado.

\section{Cactaceae Juss.}

Plantas arbustivas, arbóreas, lianescentes, epífitas ou globosas, ramos geralmente suculentos, caule segmentado em cladódios fotossintetizantes, cilíndricos, colunares, aplanados, costelados ou tuberculados, em grande parte com células parenquimáticas mucilaginosas, presença de areólas (ramos axilares que originam tricomas, espinhos, gloquídeos (Opuntioideae), gemas vegetativas e reprodutivas). Folhas presentes (Pereskia, Opuntioideae) ou ausentes, espinhos aciculados e pungentes, cilíndricos, achatados ou curvos, de margem lisa ou serreada. Inflorescências terminais ou laterais, paniculadas (Pereskia) ou região florífera não diferenciada ou cefálio lateral, anelar ou apical; flores geralmente vistosas e robustas, bissexuais, actinomorfas ou levemente zigomorfas, pericarpelo liso ou com tricomas, espinhos, gloquídeos ou revestido por brácteas, tubo floral presente ou ausente, estames numerosos; estigma dividido apicalmente em 3-12 lobos, ovário ínfero de origem receptacular, unilocular, placentação parietal. Fruto baga ou acrossarcídio, suculento, deiscente ou indeiscente, globoso, ovoide, piriforme, elipsoide ou claviforme, esbranquiçado a colorido, polpa funicular sólida, mucilaginosa, translúcida, branca a colorida, remanescentes florais presentes ou decíduos, aréolas armadas ou inermes presentes ou não; sementes geralmente numerosas, globosas, ovoides, cocleariformes, elipsoides ou piriformes, testa óssea, fibrosa (Opuntioideae) ou rígida, lisa ou rugosa, parede da testa plana, côncava ou convexa, poros intercelulares rasos ou profundamente escavados.

\section{Chave para identificação das espécies de Cactaceae do PNBN, Estado da Bahia, Brasil}

\section{Folhas bem desenvolvidas, caule não fotossintetizante}

2. Espinhos pareados forma de garra, espinhos secundários retos; flor alva; fruto globoso, amarelo a laranja, amadurecendo na planta; sementes com superfície rugosa, células isodiamétricas presentes 7. Pereskia aculeata

2. Todos os espinhos aciculados e pungentes, flor rósea a magenta, frutos piriformes, mais ou menos angulares, verdes, amadurecendo no solo e tornando-se amarelos; sementes com superfície lisa, células isodiamétricas ausentes

8. Pereskia bahiensis

1. Folhas diminutas (decíduas) ou ausentes, caule fotossintetizante

3. Folhas diminutas (decíduas), cladódio com gloquídeos (espinhos com margem serreada, irritantes) presentes

4. Cacto atingindo $15 \mathrm{~m}$ de altura ou mais, cladódio principal cilíndrico, ramificações secundárias achatadas, flores amareladas 3. Brasiliopuntia brasiliensis

4. Até $2 \mathrm{~m}$ alt., cladódio cilíndrico ou aplanado, flores avermelhadas ou púrpuras

5. Cladódio cilíndrico; flor vinácea; fruto estreitamente ovoide, avermelhado ou purpúreo, parede do ovário esverdeada ou esbranquiçadas, rosada na parte inferior. 
5. Todos os cladódios achatados; segmentos do perianto vermelhos; fruto ovoide a globoso esverdeado, branco quando maduro, parede do ovário internamente rosada 15. Tacinga werneri

3. Folhas ausentes, cladódios com espinhos aciculares (não serreados) ou plantas inermes (geralmente epífitas)

6. Cefálio presente

7. Cacto globoso, ca. $20 \mathrm{~cm}$ de altura, cefálio terminal

6. Melocactus ernestii

7. Cacto colunar, acima de $40 \mathrm{~cm}$ de altura e alcançando até $4 \mathrm{~m}$ de altura, cefálio anelar

8. Cacto arbustivo, cefálio com tricomas lanosos brancos a acizentados; 16 costelas, 7-14 × 2-6 mm; segmentos do perianto alvos 13. Stephanocereus leucostele

8. Cacto subarbustivo; cefálio com tricomas com cerdas avermelhadas; $12-14$ costelas, 1,2-4 × 1,5-2,5 mm; segmentos do perianto magenta

1. Arrojadoa penicillata

6. Cefálio ausente, região florífera não diferenciada, aréolas floríferas frequentemente glabras

9. Cacto epífito, cladódios segmentados, flores nascendo lateralmente com aréolas floríferas glabras

10. Cladódios clavados, esverdeados, 11-35 mm compr.; fruto ovoide verde claro com ápice vináceo 11. Rhipsalis hileiabaiana

10. Cladódios achatados, avermelhados, 99-157 mm compr.; fruto globoso, purpúreo, magenta ou avermelho

12. Rhipsalis russellii

9. Cacto arborescente ou arbustivo, 4 a $30 \mathrm{~m}$ de altura., cefálio ausente, região florífera não diferenciada

11. Cacto arbóreo 12 a $30 \mathrm{~m}$ de altura, 3-7 costelas; frutos amarelados

5. Cereus sp. nov.

11. Cacto arbustivo, até $10 \mathrm{~m}$ altura; frutos esverdeados, avermelhados ou magenta.

12. Cacto até $5 \mathrm{~m}$ de altura, costelas 10 ou mais, frutos costelados, verde-avermelhados

2. Brasilicereus phaeacanthus

12. Cacto acima de $5 \mathrm{~m}$ de altura, costelas 3-8, frutos não costelados, verdes, arroxeados ou totalmente vermelhos

13. Aréolas com tricomas lanosos; frutos arroxeados

9. Pilosocereus catingicola

13. Aréolas sem tricomas lanosos; frutos verdes ou vermelhos quando maduros

14. Flores com tubo floral constrito na base e ápice alargado, persistentes, segmentos do perianto externo esverdeados e internos alvos, dispostas na porção terminal; frutos verdes 10. Pilosocereus pentaedrophorus

14. Flores longamente infundibuliforme, alvas, dispostas em qualquer parte do ramo, tudo floral decíduo; frutos externamente vermelhos.

4. Cereus jamacaru

\section{Arrojadoa penicillata (Gürke) Britton \& Rose \\ Figura 2 a}

Nome popular: rabo-de-raposa

Cacto subarbustivo, colunar, ca. $2 \mathrm{~m}$ alt., verde oliva, cilíndrico, lignificado. Cladódio 7-12 mm diâm., costelas 12-14, 1,2-4 × 1,5-2,5 mm; aréolas distantes entre si 4-9 mm compr. Espinhos pungentes, cinza a marrom claro, 1 central, 4-19 mm compr., 8-10 radiais, 2-5 mm compr., espinhos próximos ao cefálio maiores, centrais 12-17 mm compr., radiais 5-6 mm compr. Cefálio apical radial 26-40 × 27-40 mm; cerdas avermelhadas a ferrugíneas. Botão floral $21 \times 6 \mathrm{~mm}$; flores diurnas, magenta, 15-23 × 3-11 mm, segmentos externos do perianto 7-9 $\mathrm{mm}$ compr., segmentos internos do perianto 8-9 mm compr., estilete $16 \mathrm{~mm}$ compr., 5 lobos estigmáticos, 2-3 mm compr., estames 7-12 mm compr.; pericarpelo $8 \times$ $5,5 \mathrm{~mm}$, ovário $2,5 \times 4 \mathrm{~mm}$. Fruto avermelhado, $14 \times 43 \mathrm{~mm}$, polpa funicular esbranquiçada, presença de restos do perianto enegrecido e rígido; sementes cocleariformes, pretas.
Arrojadoa penicillata pode ser encontrada na forma de arbusto ou subarbusto. Suas flores podem variar de magenta a um vermelho rosado, dispostas em número de 4, aproximadamente nos cefálios anelares, sementes cocleariformes pretas, 1,2 $\mathrm{mm}$ de comprimento, testa convexa (Taylor \& Zappi, 2004).

Esta espécie está distribuída nas áreas de Caatinga nos Estados da Bahia e Minas Gerais e pode ser encontrada em inselbergs, solo arenosos e pedregosos (Taylor \& Zappi 2004; Zappi \& Taylor 2019). No PNBN, a espécie é comum, com uma população de cerca de 20 indivíduos em área de Caatinga, onde foi coletada somente com flores em agosto.

Material examinado: BRASIL. BAHIA: Boa Nova, Parque Nacional de Boa Nova, Setor Leste do Parque e área de refúgio, 13-VIII-2013, fl., D.C. Zappi et al. 3469 (HURB); ibid., Fazenda Cotermaia, Região da Lagoa Danta, 14-VIII2013, fl., L.Y.S. Aona et al. 3014 (HURB). 


\section{Brasilicereus phaeacanthus (Gürke) Backeb.}

\section{Figura $2 \mathrm{~b}$}

Cacto arbustivo pouco ramificado, até $5 \mathrm{~m}$ alt., cilíndrico, verde escuro. Cladódio 15-17 mm diâm., gloquídeos presentes, costelas 10-11, 5-9 × 3-6 mm; aréolas distantes entre si 6-9 mm compr. Folhas diminutas (decíduas), espinhos 11-17, aciculados, pungentes, 10-16 radiais, 7-15 $\mathrm{mm}$ compr., 1 central, 13-24 mm compr. Cefálio ausente, região florífera não diferenciada. Flores noturnas, alvas, 13-57 $\times 15-40 \mathrm{~mm}$, segmentos externos do perianto 9-21 $\times$ 8-10 mm, segmentos internos do perianto, 14-24 × 6-9,5 $\mathrm{mm}$, ambos os segmentos esverdeados com porção apical avermelhada; estilete $38 \mathrm{~mm}$ compr., 8 lobos estigmáticos, 4-5 mm compr., estames $25-31 \mathrm{~mm}$ compr., pericarpelo, 13-14 × 15-17 mm, ovário, $8 \times 9-12 \mathrm{~mm}$. Fruto avermelhado, $32 \times 12 \mathrm{~mm}$, polpa funicular alva; sementes cocleariformes.

Brasilicereus phaeacanthus é uma espécie endêmica do Brasil, apresenta forma arbustiva ou subarbustiva com até $5 \mathrm{~m}$ de altura, em grande parte pouco ramificada (Taylor \& Zappi 2004). Apresenta uma coloração do verde escuro ao cinza esverdeado, flor tubular branca com segmentos externos verdes a avermelhados e sementes cocleariformes, com região micropilar formando um ângulo de $20^{\circ}-30^{\circ}$ (Taylor \& Zappi 2004).

Encontrada em região de Caatinga nos Estados da Bahia e Minas Gerais (Taylor \& Zappi 2004). No PNBN, apresenta população com de cerca de 10 indivíduos próximos aos lajedos, vegetação de Caatinga, onde foi coletada com flor e fruto no período de março.

Material examinado: BRASIL. BAHIA: Boa Nova, Parque Nacional de Boa Nova, Setor Oeste, Fazenda Lagedão, 03III- 2013, fl., fr., L.Y.S. Aona et al. 2225 (HURB).

Material adicional examinado: BRASIL. BAHIA: Feira de Santana, Fazenda Chapada, propriedade José Morais, 24III-2007, E. Melo. 4645 (HUEFS).

\section{Brasiliopuntia brasiliensis (Willd.) A.Berger Figura $2 \mathrm{c}$}

Nomes populares: urumbeba, rumbeba, cumbeba, mumbeca, mumbebo, facho-de-renda, palmatória-grande, palmatóriado-diabo, ambeba, arumbeva, gerumbeba, jurubeba, almadora, palmatória, xiquexique-do-sertão

Cacto arbustivo, ca. 1,5 m alt., verde escuro. Cladódio 4-11 mm diâm., cilíndrico, ramificações secundárias achatadas, 56-272 x 6-21 mm. Presença de gloquídeos. Espinhos aciculados, pungentes, 9-11 mm compr. Cefálio ausente, região florífera não diferenciada. Botão floral 23 x $13 \mathrm{~mm}$; flores diurnas, amarelas, 27-31 x 10-14 mm; estilete, $13-15 \mathrm{~mm}$ compr., 3 lobos estigmáticos curvados, 2-3 mm compr.; estames 4-9 mm compr.; pericarpelo, 9-10 x 6-7 mm, ovário, 5 x 2,5 mm (Taylor \& Zappi 2004). Fruto piriforme, amarelado a vermelhado, $21 \times 36 \mathrm{~mm}$, polpa funicular esbranquiçada, pequenos gloquídeos presentes (Taylor \& Zappi 2004).

Brasiliopuntia brasiliensis é caracterizada por possui ramificação primária cilíndrica da qual origina segmentos secundários aplanados. Flores geralmente dispostas no ápice da parte aérea, fruto solitário de coloração que pode variar do amarelo ao vermelho, sementes 1-5 por frutos, $8-10 \mathrm{~mm}$ de comprimento (Taylor \& Zappi 2004).

Espécie distribuída nos Biomas Amazônia, Caatinga, Cerrado, Mata Atlântica e Pantanal do Brasil. Sua ocorrência é predominante na região Nordeste, mas também ocorre em regiões do Norte com registros apenas para o Estado de Rondônia, na região Centro-Oeste para os Estados do Mato Grosso do Sul e Mato Grosso, nas regiões Sudeste e Sul (Zappi \& Taylor 2020). No PNBN, esta espécie ocorre na área de Caatinga, presença de poucos indivíduos, cerca de 4-5. Não foi possível coletar esta espécie com flores e frutos.

Material examinado: BRASIL. BAHIA: Boa Nova, Parque Nacional de Boa Nova, Setor Oeste, Fazenda Lajedão. 05I-2013, L.Y.S. Aona et al. 1856 (HURB); Ibid., Fazenda Cotermaia, Região da Lagoa Danta. 14-VIII-2013, L.Y.S. Aona et al. 3002 (HURB).

Material adicional examinado: BRASIL. BAHIA: Feira de Santana, Fazenda Retiro, ca. de $18 \mathrm{Km}$ de Feira de Santana na Estrada do feijão, sentido Ipirá, Anguera, 22-V-2007, fl., fr., D. Cardoso 1939 (HUEFS).

\section{Cereus jamacaru DC. subsp. jamacaru}

Figuras 2 d, 3 a-b.

Nome popular: mandacaru, mandacaru-de-boi, mandacarufacheiro, mandacaru-de-faixo, cardeiro, jamacaru, jamaracurú, jumucurú, jumarucú, cumbeba, urumbeba

Planta arbórea, ca. 4-10 m alt., colunar, verde azulado, acinzentado quando lignificado. Cladódio $86-90 \mathrm{~mm}$ diâm.; costelas 3-6, 46-56 × 9-14 mm, aréolas distantes entre si 17-66 mm compr. Espinhos pungentes 4-19, 5-77 $\times$ 0,8-1,8 mm. Cefálio ausente, região florífera não diferenciada. Botões florais com segmentos externos do perianto esverdeados, $71-117 \times 17-22 \mathrm{~mm}$; flores noturnas, alvas, longamente infundibuliformes, $145 \times 52 \mathrm{~mm}$, tubo floral decíduo, estilete $120 \mathrm{~mm}$ compr., estames 42,5-52 $\mathrm{mm}$ compr. Fruto avermelhado quando maduro, 34-90,1 $\times$ 12,5-68,5 mm, polpa funicular esbranquiçada; sementes cocleariformes, pretas, brilhantes, 2,1-4,7 × 1,5-3,2 mm, superfície rugosa, testa com parede periclinal fortemente convexa, crateras presentes.

Cereus jamacaru apresenta cladódio com coloração verde escuro e acinzentado, flores dispostas geralmente em qualquer parte dos ramos (Taylor \& Zappi 2004).

Esta espécie apresenta distribuição predominantemente na região Nordeste, mas também ocorre em regiões do Norte como em Tocantins, Centro-Oeste em Goiás e no Sudeste nos 
Estados de Minas Gerais e Rio de Janeiro (Zappi \& Taylor 2020). No PNBN, C. jamacaru é bastante representativo ao longo do PNBN, podendo encontrar exemplares desde a beira de estradas até as áreas de Floresta Semidecidual (agreste), onde foi coletada com flores e frutos em agosto (Taylor \& Zappi 2004).

Material examinado: BRASIL. BAHIA: Boa Nova, Parque Nacional de Boa Nova, Fazenda Travessão e Fazenda lagedão, Mata da Torre ou Pioneira, 13-VIII-2013, L.Y.S. Aona et al. 3052 (HURB); Ibid., Setor Central, Fazenda Alvorada, perto do lajedo dos Beija-flores, 02-III-2013, L.Y.S. Aona et al. 2121 (HURB); Ibid., Setor Leste, Fazenda Cotermaia, Região da Lagoa Danta 14-VIII-2013, fl., fr., L.Y.S. Aona et al. 3004 (HURB).

Material adicional examinado: BRASIL. BAHIA: Contendas do Sincorá, Flona, 50m da sede, Via Rio Combuca, 02-XI2015, fl., L.Y.S. Aona et al. 3856 (HURB); Santa Teresinha, 19-VIII-2015, fl., fr., S.S. Simões et al. (HURB 9661). SERGIPE: Assentamento Nossa Senhora da Glória, 20-VI2006, fl., A.P. Prata et al. 3638 (HURB); Gracho Cardoso, 26-V-2010, G.G. Conceição et al. 31 (HURB).

\section{Cereus sp.}

Figura $2 \mathrm{e}$

Cacto arbóreo, ca. 12-30 m alt., verde escuro, acinzentado quando lignificado. Cladódio 91-96 mm diâm.; costelas 3-7, 34-57,5 × 3-7- mm, indivíduos jovens 3-costelas, indivíduos adultos 7-costelas. Cefálio ausente, região florífera não diferenciada; aréolas, distantes entre si 27-64 mm compr. Flores e sementes não vistos. Frutos amarelados (Taylor \& Zappi 2004).

Cereus sp. é um táxon ainda não descrito para o Estado da Bahia, com primeiro registro para o município de Vitória da Conquista (Taylor \& Zappi 2004). Apresenta hábito arbóreo, lignificado e flores robustas (Taylor \& Zappi 2004). Quando jovem, apresenta geralmente 3 costelas finas, e 7 costelas na fase adulta. Há registros de frutos amarelados (Zappi, comm. pess.), mas neste estudo não apresentamos informações sobre flores, frutos e sementes pela amostra estar estéril no momento em que o exemplar foi coletado. Entretanto, essa espécie já está em vias de publicação.

No PNBN, também há registros de Cereus sp. em área de Floresta Semidecidual, a qual apresenta um indivíduo com ca. $30 \mathrm{~m}$ de altura.

Material examinado: BRASIL. BAHIA: Boa Nova, Parque Nacional de Boa Nova, Setor Central, Fazenda Alvorada, perto do Lajedo dos Beija-flores, 02-III-2013, L.Y.S. Aona et al. 2118 (HURB); Ibid., perto do Lajedo dos Beija-flores, 02-III-2013, L.Y.S. Aona et al. 2121 (HURB).

\section{Melocactus ernestii Vaupel subsp. ernestii}

\author{
Figuras 2 f, 3 c-d
}

Cacto globoso, ca. $20 \mathrm{~cm}$ alt., verde escuro. Cladódio 12,1 cm diâm.; costelas 10-12, 43-50 × 11,5-28,5 mm; aréolas distantes entre si 12-17 mm compr. Espinhos 10-13 radiais, curvados, 10-32 × 0,5-1,2 mm, 1 radial inferior, 41-57 $\times$ 1-1,5 mm, 3-4 centrais, 15-32 × 1-1,2 mm. Cefálio circular, terminal, tricomas brancos com cerdas avermelhadas, 13-81 $\times$ 30-76 mm diâm. Flores diurnas, magenta, 14,5-17 × 4,5 mm, segmentos externos do perianto 5-6 $\mathrm{mm}$ compr., segmentos internos do perianto 4,5-5 $\mathrm{mm}$ compr.; estilete, $11 \mathrm{~mm}$ compr., estames 2-2,5 mm compr.; ovário, $2,5 \times 3,5 \mathrm{~mm}$; pericarpelo $4 \mathrm{~mm}$ compr. Fruto magenta $13-13,5 \times 5-5,5 \mathrm{~mm}$, presença de remanescentes florais; sementes cocleariformes, pretas, brilhantes, 0,3-0,5 $\times 0,2-0,4 \mathrm{~mm}$, superfície rugosa, testa com parede periclinal convexa, crateras presentes.

Melocactus ernestii é subdividida em duas subespécies, subsp. ernestii Vaupel e subsp. longicarpus (Buining \& Brederoo). A subsp. ernestii é encontrada nos Estados de Alagoas, Bahia, Paraíba, Pernambuco e Sergipe e se diferencia da subsp. longicarpus pelo número de costelas e pela quantidade de espinhos centrais, onde subsp. ernestii apresenta de 10-13(-15) costelas e 1-4(-6) espinhos centras enquanto subsp. longicarpus ocorre na Caatinga dos Estados da Bahia e Minas Gerais e apresenta de 9-11 costelas e de 4-8 espinhos centrais (Taylor \& Zappi 2004; Zappi \& Taylor 2020).

Esta espécie apresenta grande interesse ornamental e de colecionadores nacionais e internacionais (Zappi et al. 2011). Ao logo da BR 116 e BA 052 no Estado da Bahia, é muito comum o comércio de espécies de Melocactus, colocando em risco as populações locais ocorrentes em afloramentos rochosos os quais já sofrem com os impactos e degradação da Caatinga (Zappi et al. 2011). São encontradas geralmente em inselbergs e em outros lugares rochosos (Taylor \& Zappi 2004).

Melocactus ernestii é uma espécie endêmica do Brasil, encontrada nos biomas Caatinga e Mata Atlântica, na região Nordeste e Sudeste do país (Zappi et al. 2016). No PNBN, a espécie se encontrava em lajedos na área de Caatinga, em uma população com mais de 50 indivíduos, onde foi coletada com flores e frutos em agosto e janeiro.

Material examinado: BRASIL, BAHIA: Boa Nova, Parque Nacional de Boa Nova, Setor Oeste, Fazenda Lagedão, 05I-2013, fl., fr., L.Y.S. Aona et al. 1855 (HURB); ibid., região da Lagoa Danta, Lajedo do seu Zequinha, 14-VIII-2013, fl., fr., L.Y.S. Aona et al. 3003 (HURB); ibid., Setor Central, Fazenda Alvorada, Lajedo dos Beija-flores, 02-III-2013, L.Y.S. Aona et al. 2161 (HURB).

Material adicional examinado: BRASIL. BAHIA: Milagres, Acima do morro da Igreja de São Cristóvão, em direção ao topo, 19-VIII-2015, fl., fr., S.S. Simões et al. 169 (HURB). 


\section{Pereskia aculeata Mill.}

Figuras 2 g, 3 e-f

Nomes populares: pra-pro-nobis, azedinha, lobolôbô, sspinho-de-santo-antônio, espinho-preto, surucucú, cipósanto

Cacto lianescente, ramificações irregulares, lignificado. Espinhos pareados, primários em forma de garra, 4,56,5 × 1,5-4 mm, secundários retos. Folhas alternas, bem desenvolvidas, pecioladas, nervuras laterais presentes, elípticas, 34-41 × 12-18 mm. Inflorescência paniculada, quando jovem de cor esverdeada, $5,2 \times 10 \mathrm{~mm}$; flores diurnas, alvas, $35 \times 34 \mathrm{~mm}$, ambas apresentam espinhos pungentes saindo do pericarpelo. Fruto globoso, 1120,5 × 11,1-20 mm, disposto em infrutescência ou isolados, amarelo a alaranjado quando maduro, amadurecendo na planta, espinhos presentes; sementes lenticulares, 8,4-9,2 $\mathrm{x} 8,0-8,8 \mathrm{~mm}$, quando jovens amarronzadas, brilhantes, quando maduras pretas, brilhantes, superfície rugosa, fracamente convexa, células isodiamétricas presentes, crateras ausentes.

Pereskia aculeata apresenta flores alvas a creme, forte perfume de diosmina, os ramos frutíferos são frequentemente coletados na ausência de folhas durante a estação seca (Zappi et al. 2007; Taylor \& Zappi 2004). No Nordeste do Brasil é muito utilizada como cerca viva (Taylor \& Zappi 2004).

Está presente no Brasil em áreas de Caatinga, Cerrado e Mata Atlântica na região Nordeste nos Estados de Alagoas, Bahia, Ceará, Maranhão, Pernambuco, Sergipe, no CentroOeste no Estado de Goiás, no Sudeste e Sul do País (Zappi $\&$ Taylor 2020). No PNBN, a espécie ocorre naturalmente em uma população média em áreas de Floresta Estacional Semidecidual e afloramento rochoso, onde foi coletada com flores em março e frutos em março e outubro.

Material examinado: BRASIL. BAHIA: Boa Nova, Parque Nacional de Boa Nova, Setor Central, Fazenda Alvorada, Lajedo dos Beija-flores, 02-III-2013, fr., L.Y.S. Aona et al. 2148 (HURB); Ibid., Lajedo a $500 \mathrm{~m}$ da estrada, 06-X-2012, fl., fr., L.Y.S. Aona et al. 1687 (HURB).

Material adicional examinado: BRASIL. BAHIA: Cruz das Almas, 30.IV.1981, fl., fr., G.C.P. Pinto 83 (HRB).

\section{Pereskia bahiensis Gürke}

Figuras 2 h, 3 g-h

Nomes populares: quiabento (quiá-bento), inhabento, jumbeba, surucurú, flor-de-cera, espinho-de-santo-antônio, entrada-de-baile, ora-pro-nobis

Cacto arbóreo ca. $3 \mathrm{~m}$ alt.; ca. $20 \mathrm{~cm}$ diâm.; aréolas distantes entre si $9-43 \mathrm{~mm}$ compr. Espinhos 8 , todos aciculados, pungentes, 7-32 mm compr. Folhas bem desenvolvidas, alternas, elípticas ou oblongas, 44-120 $\times$ 20-65 mm. Inflorescência cimosa paniculada, 2-12 flores ou flores solitárias; Flores diurnas, terminais, rósea a magenta. Fruto piriforme, mais ou menos angular, verde quando jovem, amadurecendo no solo e tornando-se amarelo, 31,1-39 $\times 21-38 \mathrm{~mm}$, disposto em infrutescência com até 12 frutos ou frutos solitários; sementes lenticulares, 6,3-6,8 $\times$ 4,2-4,8 mm, pretas, brilhantes, superfície lisa, fracamente convexa, crateras e células isodiamétricas ausentes.

Pereskia bahiensis apresenta inflorescência cimosa paniculada, na porção terminal, flor, $40-70 \mathrm{~mm}$ de diâm., receptáculo na forma de cone, estames, 5-10 $\mathrm{mm}$ compr., 5-10 lobos estigmáticos, ovário, 7-10 mm diâm. (Taylor \& Zappi 2004). A espécie é muito utilizada como cerca viva (Zappi et al. 2011).

É uma espécie endêmica do Estado da Bahia, com ocorrência para as áreas de Caatinga em torno da Chapada Diamantina, Planalto de Maracás, Norte da Serra do Espinhaço e região Leste e Sul do Rio São Francisco (Taylor \& Zappi 2004; 2008). No PNBN, a espécie ocorre naturalmente em uma população média nas áreas de transição de Caatinga e Floresta Estacional Semidecidual, onde foi coletada com frutos no período agosto.

Material examinado: BRASIL. BAHIA: Boa Nova, Parque Nacional de Boa Nova, Fazenda Travessão e Fazenda Lagedão, Mata da Torre ou Pioneira, 13-VIII-2013, fr., L.Y.S. Aona et al. 3051 (HURB); Ibid., Setor Leste, Fazenda Cotermaia, Região da Lagoa Danta, 14-VIII-2013, L.Y.S. Aona et al. 3001 (HURB).

Material adicional examinado: BRASIL. BAHIA: Contendas do Sincorá, Floresta Nacional Contendas do Sincorá, 04IV-2014, L.Y.S. Aona et al.3549 (HURB); Ibid., a $15 \mathrm{Km}$ do Rio Preto em direção ao Riacho do Mel, 19-III-1980, J.E. Brazão 165 (HURB); Manoel Victorino, Serra da Pipoca, 15-I-1984, fl., fr., G.C.P. Pinto 65 (HURB).

\section{Pilosocereus catingicola (Gürke) Byles \& Rowley subsp. catingicola}

Figuras $2 \mathrm{i}, 3 \mathrm{i}-\mathrm{j}$

Nomes populares: facheiro, mandacaru-babão, mandacarude-facho

Cacto arbustivo ca. $8 \mathrm{~m}$ alt., verde oliva, lignificado. Cladódio, 54-79 mm diâm., costelas 5, 26-32 × 12-21 mm; aréolas distantes entre si 12 a $18 \mathrm{~mm}$ compr., tricomas lanosos presentes. Espinhos centrais aciculados, pungentes, 9-20 $\times$ 0,9-1,0 mm, espinhos radiais curtos, 3-7 mm compr. Cefálio ausente, região florífera não diferenciada. Flores noturnas, alvas, 44-57 $\times 14-29 \mathrm{~mm}$, segmentos externos do perianto esverdeados, 7-18, $5 \times 6,5-12 \mathrm{~mm}$, tubo floral persistentes, segmentos internos do perianto alvos, 14-23 $\times$ 4-6,2 mm; estilete, 34-54 mm compr., 13 lobos estigmáticos, 2,8-5,5 mm compr., estames 6-25 mm compr.; pericarpelo, 6-10,5 × 11,8-13 mm, ovário, 3-4,2 × 8,4-11 mm. Fruto globoso, arroxeado, $45 \times 60 \mathrm{~mm}$, polpa funicular magenta; 
sementes cocleariformes, pretas, 1,5-1,7 $\times 1,0-1,1 \mathrm{~mm}$., superfície fracamente rugosa, testa fracamente convexa, crateras presentes.

Pilosocereus catingicola apresenta duas subespécies, a subp. catingicola e a subp. salvadorensis (Werderm.) Zappi. A subsp. catingicola apresenta forma arbustiva e com registro apenas para áreas de Caatinga do Estado da Bahia e se diferencia da subsp. salvadorensis por apresentar de 4-6 costelas e espinhos robustos com 10-40 mm compr., enquanto a subsp. salvadorensis apresenta forma de vida arbustivo ou arbóreo e com registro para os Estados Alagoas, Bahia, Ceará, Paraíba, Pernambuco, Rio Grande do Norte e Sergipe e apresentam de (-5) 6-12 costelas e espinhos delgados com 2-10 mm de comprimento.

Pilosocereus catingicola é endêmica do Brasil, com registro para as áreas de Caatinga e Mata Atlântica do Nordeste brasileiro (Zappi \& Taylor 2020). No PARNA, P. catingicola é encontrado em diversas áreas do Parque, como Floresta Estacional Semidecidual e Caatinga, com populações de ca. 3-5 indivíduos distribuídas ao longo das trilhas e dentro da vegetação, onde foi coletada com flor e fruto no período de março.

Material examinado: BRASIL. BAHIA: Boa Nova, Parque Nacional de Boa Nova, Setor Central, Fazenda Alvorada, perto do Lajedo dos Beija-flores, fl., fr., 02-III-2013, L.Y.S. Aona et al. 2098 (HURB).

\section{Pilosocereus pentaedrophorus subsp. robustus Zappi} Figura $2 \mathrm{j}$

Nomes populares: facheiro, facheiro-fino, mandacaru-deveado

Cacto arbustivo, ca. $5 \mathrm{~m}$ alt., verde azulado, cilíndrico, lignificado. Cladódio 16-34 mm diâm. Costelas 6-8, 14,2-30 × 7-11 mm; aréolas distantes entre si $8-20 \mathrm{~mm}$ compr. Espinhos (7-) 8-12 (-13), 2-9 mm $\times$ 0,2-0,6 mm. Cefálio ausente, região florífera não diferenciada. Botão floral, $15-16 \times 36-40 \mathrm{~mm}$; flores diurnas, tubo floral constrito na base e ápice alargado, persistentes, segmentos do perianto externo esverdeados e internos alvos, estames 30-32 mm compr., estilete 40-42 mm compr., pericarpelo, $8 \times 11-11,5$ $\mathrm{mm}$. Fruto globoso, levemente depresso, verdes, $19 \times 21$ $\mathrm{mm}$, polpa funicular magenta; sementes com superfície da parede da testa plana.

Pilosocereus pentaedrophorus apresenta duas subespécies a subp. pentaedrophorus (Cels) Byles \& Rowley que pode apresentar forma arbustiva ou liana e subsp. robustus que apresenta forma arbustiva, onde a principal diferença entre essas duas subespécies está na quantidade de costelas, onde a subsp. pentaedrophorus apresenta 4-6(-7) costelas e registro para as áreas de Caatinga e Mata Atlântica nos Estados de Bahia, Pernambuco e Sergipe e a subsp. robustus apresenta
(5-) 6-10 costelas com registro para áreas de Caatinga e Mata Atlântica nos Estados da Bahia e Minas Gerais (Taylor \& Zappi 2004; Zappi \& Taylor 2020).

Pilosocereus pentaedrophorus é uma espécie endêmica do Brasil, com registro para o Nordeste nos Estados de Bahia, Pernambuco e Sergipe e Sudeste no Estado de Minas Gerais (Zappi \& Taylor 2020). No PARNA, P. pentaedrophorus apresenta uma população representativa com mais de 20 indivíduos em área de Floresta Semidecidual, onde foi coletada com flor e fruto no período março.

Material examinado: BRASIL. BAHIA: Boa Nova, Parque Nacional de Boa Nova, Setor Central, Fazenda Alvorada, perto do Lajedo dos Beija-flores, 03-III-2013, fl., fr., L.Y.S. Aona et al. 2098 (HURB).

Material adicional examinado: BRASIL. BAHIA: Estrada vicinal de Contendas do Sincorá pra Palmeiras, Contendas do Sincorá, 07-II-2015, fl., L.Y.S. Aona et al. 3995 (HURB).

\section{Rhipsalis hileiabaiana (N.P.Taylor \& Barthlott) N.} Korotkova \& Barthlott

Figura $2 \mathrm{k}$

Nomes populares: enxerto, conambaia, tripa-de-galinha, irahuka'arã

Cacto epífito. Cladódios esverdeados, clavados, segmentados, 11-35 mm compr. Cladódios basais, 11,5$18,9 \mathrm{~cm}$ compr., verde-claros. Flores diurnas, nascendo lateralmente com aréolas floríferas glabras. Flores não vistas. Frutos ovoides, verde-claros, ápice ou completamente vináceos, 4,5-7 × 3,5-6 mm; sementes pretas a acastanhadas, $1,2 \times 0,6 \mathrm{~mm}$.

Rhipsalis hileiabaiana apresenta forma de erva, epífita ou subarbustiva é uma espécie endêmica para o Estado da Bahia ocorrente em áreas de Mata Atlântica (Zappi \& Taylor 2020). Com distribuição para a região de Catolés, Chapada Diamantina, e região Central e Oriental da Bahia (Taylor \& Zappi 2004). Apresenta flores brancas esverdeadas, 6-7 x 4-5 $\mathrm{mm}$, estames com 1-2,5 mm compr., 3 lobos estigmáticos e o fruto ovoide variando da coloração branca a rosa (Taylor \& Zappi 2004).

Espécie endêmica da Bahia, ocorrendo em Campo Rupestre, Floresta Ombrófila e restinga (BFG, 2018). No PNBN, R. hileiabaiana foi encontrado um único indivíduo em área de Mata Atlântica. No local de estudo, esta espécie foi coletada somente com frutos imaturos em agosto.

Material examinado: BRASIL. BAHIA: Boa Nova, Parque Nacional de Boa Nova, Setor Sul, Ramal para a Fazenda Liberdade, Setor da Farofa, 14-VIII-2013, fr., L.Y.S. Aona et al. 2982 (HURB).

Material adicional examinado: BRASIL. BAHIA: Abaíra, 16-XI-1992, fr., W. Ganev 1468 (HUEFS). 

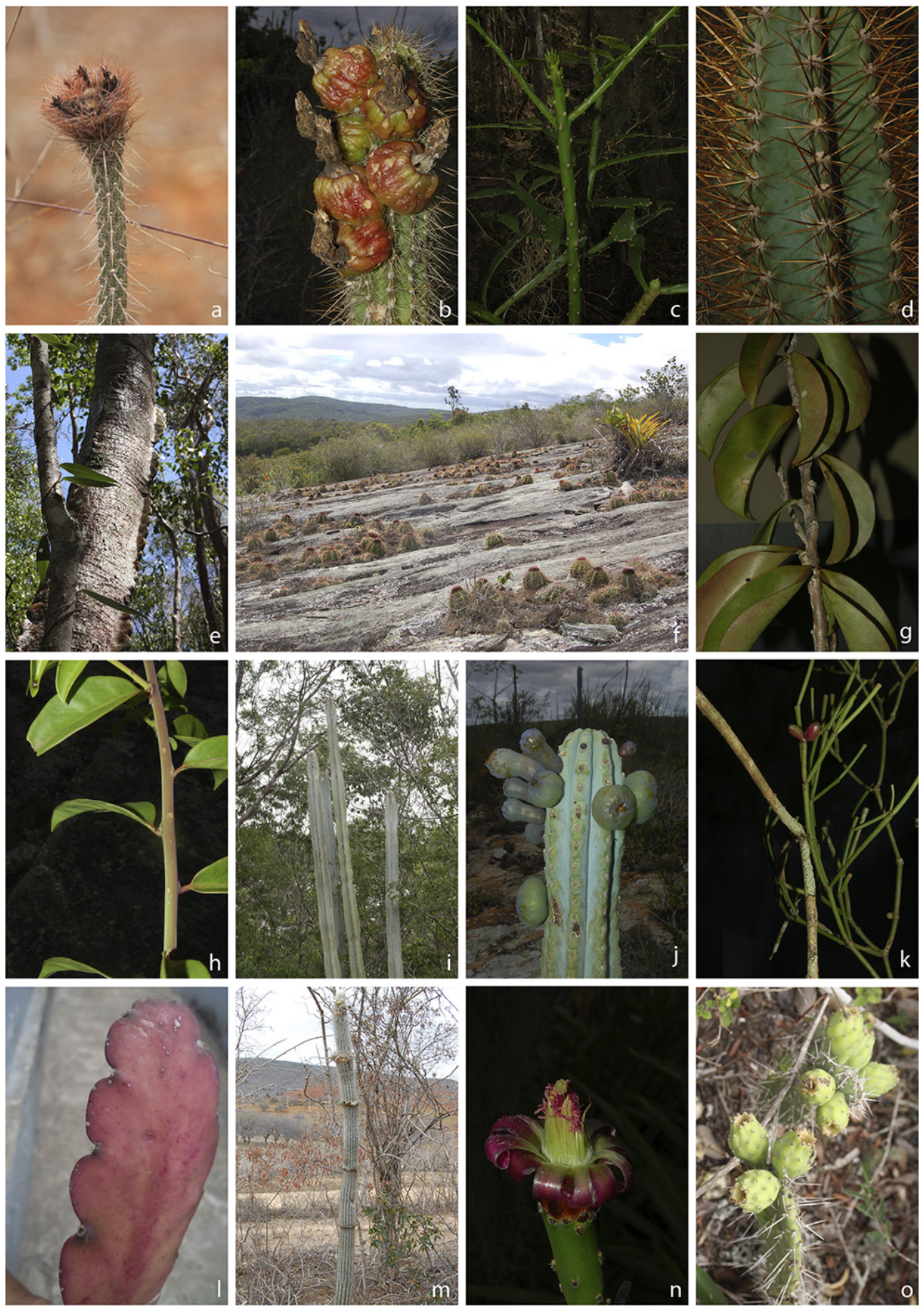

Figura 2. Espécies de Cactaceae do Parque Nacional de Boa Nova, Estado da Bahia, Brasil. a. Arrojadoa penicillata (Gürke) Britton \& Rose. b. Brasilicereus phaeacanthus (Gürke) Backeb. c. Brasiliopuntia brasiliensis (Willd.) A.Berger. d. Cereus jamacaru DC. e. Cereus sp. f. Melocactus ernestii Vaupel. g. Pereskia aculeata Mill. h. Pereskia bahiensis Gürke. i. Pilosocereus catingicola (Gürke) Byles \& Rowley. j. Pilosocereus pentaedrophorus (Cels) Byles \& Rowley subsp. robustus Zappi. k. Rhipsalis hileiabaiana (N.P.Taylor \& Barthlott) N. Korotkova \& Barthlott. 1. Rhipsalis russellii Britton \& Rose. m. Stephanocereus leucostele (Gürke) A.Berger. n. Tacinga funalis Britton \& Rose. o. Tacinga werneri (Eggli) N.P.Taylor \& Stuppy.

Figure 2. Species of Cactaceae in the Parque Nacional de Boa Nova, Bahia State, Brazil. a. Arrojadoa penicillata (Gürke) Britton \& Rose. b. Brasilicereus phaeacanthus (Gürke) Backeb. c. Brasiliopuntia brasiliensis (Willd.) A.Berger. d. Cereus jamacaru DC. e. Cereus sp. f. Melocactus ernestii Vaupel. g. Pereskia aculeata Mill. h. Pereskia bahiensis Gürke. i. Pilosocereus catingicola (Gürke) Byles \& Rowley. j. Pilosocereus pentaedrophorus (Cels) Byles \& Rowley subsp. robustus Zappi. k. Rhipsalis hileiabaiana (N.P.Taylor \& Barthlott) N. Korotkova \& Barthlott. 1. Rhipsalis russellii Britton \& Rose. m. Stephanocereus leucostele (Gürke) A.Berger. n. Tacinga funalis Britton \& Rose. o. Tacinga werneri (Eggli) N.P.Taylor \& Stuppy. 


\section{Rhipsalis russellii Britton \& Rose}

Figura 21

Nome popular: Mandacaru-da-serra

Cacto epífito. Cladódios achatados, elípticos, avermelhados, 99-157 × 45-49 mm, ramificados a partir das aréolas apicais e laterais; aréolas distantes entre si 12$32 \mathrm{~mm}$ compr. Botões florais esbranquiçados ou rosados, geralmente 3-9 botões por aréolas; flores diurnas, saindo lateralmente com aréolas floríferas glabras, esbranquiçadas ou rosadas. Fruto agrupado, globoso, 5,9-10 $\times 5-8 \mathrm{~mm}$, purpúreo, magenta ou avermelhado; sementes não vistas.

Rhipsalis russellii apresenta botões florais que variam do esbranquiçado ao roxo, $7 \times 5,9 \mathrm{~mm}$, estames $2-3 \mathrm{~mm}$ compr., 3-6 lobos estigmáticos, 1-1,5 mm compr., pericarpelo, $2 \times 3$ $\mathrm{mm}$. Frutos globosos, agrupados, $7 \mathrm{~mm}$ de diâmetro, quando jovens varia do esbranquiçado ao rosa pálido e maduros varia do rosa magenta ao roxo (Taylor \& Zappi 2004).

É uma espécie endêmica do Brasil com ocorrência para as áreas de Caatinga, Serrado e Mata Atlântica nos Estados da Bahia, Goiás, Mato Grosso, Espírito Santos, Minas Gerais, Rio de Janeiro e Paraná (Zappi \& Taylor 2020). No PNBN a espécie foi encontrada estéril sobre uma palmeira em área de afloramento rochoso em Floresta Estacional Semidecidual, não sendo observados em outros ambientes ou outros indivíduos.

Material examinado: BRASIL. BAHIA: Boa Nova, Parque Nacional de Boa Nova, Setor Central, Fazenda Alvorada, Lajedo dos Beija-flores, 02-III-2013, L.Y.S. Aona et al. 2150 (HURB).

Material adicional examinado: BRASIL. BAHIA: Trilha para Cachoeira do Ramalho, Serra do Sincorá, Andaraí, 06-VIII2001, fr., F.R. Nonato 1015 (HUEFS); Rio Mandassaia, Barro Branco, Parque Nacional da Chapada Diamantina, Lençóis, 22-I-2000, fr., A.A. Ribeiro-Filho 05 (HUEFS).

\section{Stephanocereus leucostele (Gürke) A.Berger}

Figuras $2 \mathrm{~m}, 3 \mathrm{k}-1$

Cacto arbustivo, colunar, ca. $4 \mathrm{~m}$ alt., cilíndrico, cinza esverdeado, ramificações nas articulações quando presentes. Cadódio, 29-32 mm diâm.; costelas 16, 7-14 × 2-6 mm.; aréolas distantes entre si 8-10 mm compr., tricomas lanosos presentes. Espinhos 13-29, levemente dourados, 9-18 mm compr.; espinhos superiores, $20-29 \times 0,3-0,7 \mathrm{~mm}$. Cefálio anelar, 25-41 $\times 32-60 \mathrm{~mm}$, tricomas lanosos brancos a acinzentados presentes. Flores noturnas, alvas, $34 \times 19$ $\mathrm{mm}$, segmentos do perianto alvos, estilete, $50 \mathrm{~mm}$ compr., estames $33 \mathrm{~mm}$ compr. Fruto globular, azulado 36-60 $\times$ 21-40 mm, polpa translúcida; sementes cocleariformes, castanhas, opacas 1,7-1,9 × 1,2-1,6, superfície rugosa, testa com parede periclinal totalmente convexa, células isodiamétricas pressentes, cratera ausente.
Stephanocereus leucostele é uma espécie endêmica para as áreas de Caatinga do Estado da Bahia (Zappi \& Taylor 2020). Com registros para o Cento Sul da Bahia, em áreas de Caatinga da Chapada Diamantina, no Norte da Serra do Espinhaço e Serra Geral e ao Leste do Rio São Francisco (Taylor \& Zappi 2004; 2008).

No PNBN, S. leucostele ocorre nas áreas de Caatinga com uma população com de cerca de de 10 indivíduos, sendo coletada com flor e fruto no período de agosto.

Material examinado: BRASIL. BAHIA: Boa Nova, Parque Nacional de Boa Nova, Setor Leste do Parque e área de refúgio, 13-VIII-2013, fl., fr., D.C. Zappi \& J.G. Jardim 3468 (HURB).

Material adicional examinado: BRASIL. BAHIA: Contendas do Sincorá, Flona, ramal contrário a grade de entrada para a sede, 06-II-2015, fl., L.Y.S. Aona et al. 3966 (HURB).

\section{Tacinga funalis Britton \& Rose} Figura $2 \mathrm{n}$

Nomes populares: rabo-de-rato, rabo-de-gato, cipó-deespinho, quipá-voador, trança-perna

Cacto lianescente, até ca. $2 \mathrm{~m}$ alt., segmentos do caule cilíndrico ou aplanado, verde acizentado ou avermelhado. Cladódio verde-vináceo, 2-14 mm diâm., internamente oco, base geralmente lignificada. Folhas diminutas (decíduas), ausência de espinhos; gloquídeos numerosos, amarronzados a cinza. Cefálio ausente, região florífera não diferenciada. Flores diurnas, terminais ou próximo ápice, 21-80 × 5-54 $\mathrm{mm}$, vináceas, estilete, 27 mm compr.; estames numerosos, 13,5-18 mm compr. Fruto estreitamente ovoide, avermelhado ou purpúreo, parede do ovário esverdeada ou esbranquiçadas, rosada na parte inferior; sementes não vistas.

Tacinga funalis apresenta forma de arbusto ou liana com até $12 \mathrm{~m}$ de altura, frutos avermelhados ou púrpura em forma de garrafa, $40-50 \times 20 \mathrm{~mm}$, sementes, $4 \mathrm{~mm}$ de diâmetro (Taylor \& Zappi 2004). Sementes não foram encontradas no material examinado e nenhuma informação foi encontrada na literatura.

É uma espécie endêmica do Nordeste brasileiro, com registro apenas para áreas de Caatinga do Nordeste, nos Estados da Bahia, Pernambuco e Piauí (Taylor \& Zappi 2004; Zappi \& Taylor 2020). No PNBN, esta espécie foi encontrada em uma pequena população na área de Caatinga ao longo do parque, com poucos indivíduos (ca. 15), onde foi coletada com flor no período de agosto.

Material examinado: BRASIL. BAHIA: Boa Nova, Parque Nacional de Boa Nova, Setor Leste do Parque e área de refúgio, 13-VIII-2013, fl., D. Zappi \& J. Jardim 3470 (HURB); Ibid., Região da Lagoa Danta, 14-VIII-2013. L.Y.S. Aona et al. 2999 (HURB). 

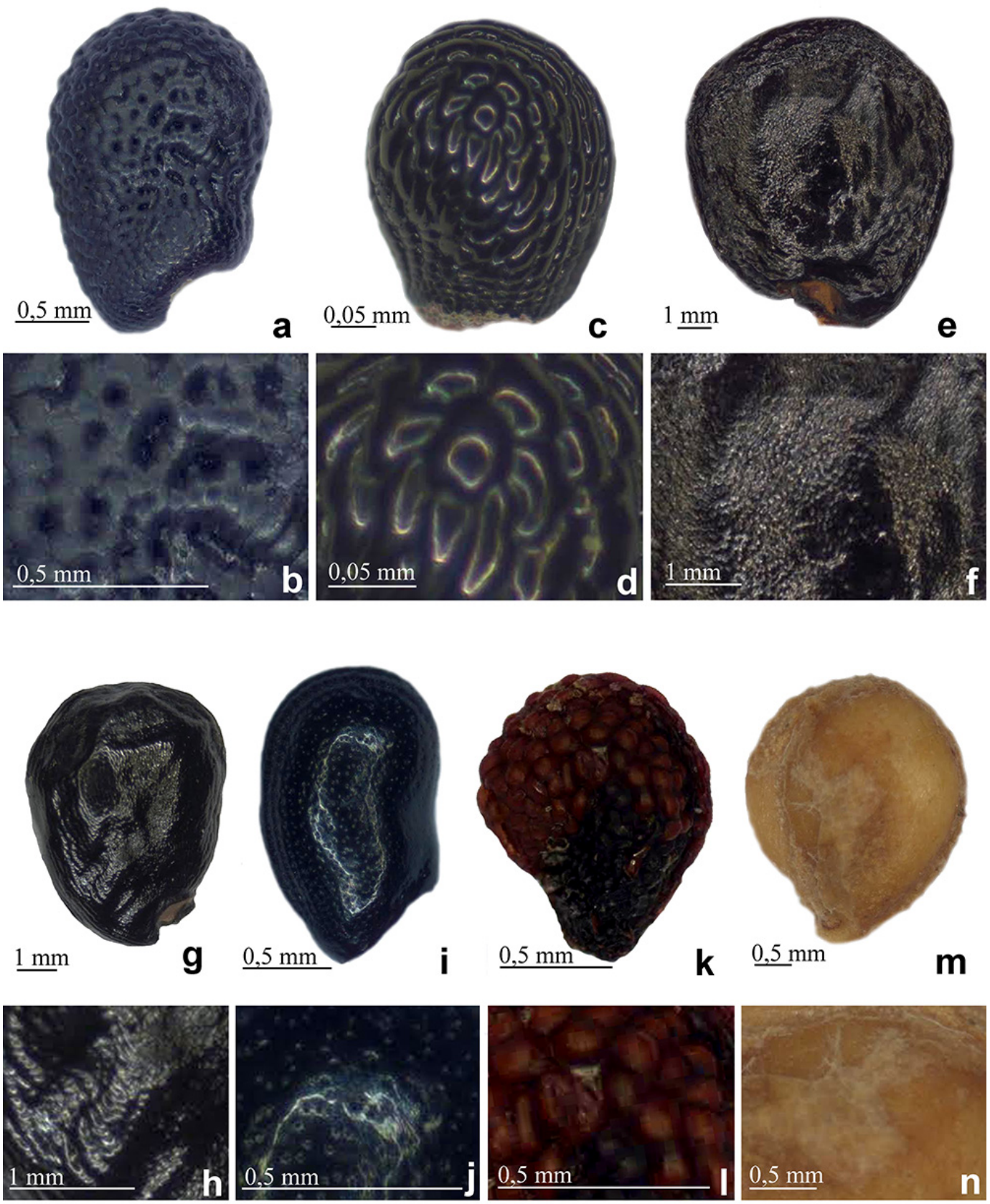

Figura 3. a-b. Cereus jamacaru DC., semente cocleariforme, preta brilhante, superfície rugosa, parede periclinal fortemente convexa, crateras presentes. c-d. Melocactus ernestii Vaupel, semente cocleariforme, preta brilhante, superfície rugosa, parede periclinal convexa, crateras presentes. e-f. Pereskia aculeata Mill., semente lenticular, preta, brilhante, superfície rugosa, fracamente convexa, células isodiamétricas presentes, crateras ausentes. g-h. Pereskia bahiensis Gürke, semente lenticular, preta brilhante, superfície lisa, crateras ausentes, células isodiamétricas ausentes e fracamente convexa. i-j. Pilosocereus catingicola (Gürke) Byles \& Rowley, semente cocleariforme, preta, superfície fracamente rugosa, fracamente convexa, crateras presentes. k-1. Stephanocereus leucostele (Gürke) A.Berger, semente cocleariforme, castanha, opaca, superfície rugosa, testa apresenta parede periclinal totalmente convexa, células isodiamétricas presentes, crateras ausentes. m-n. Tacinga werneri (Eggli) N.P.Taylor \& Stuppy, semente esférica, acastanhada, opaca, superfície lisa, crateras ausentes.

Figure 3. a-b. Cereus jamacaru DC., black, shiny cochleariform seed with periclinal walls strongly convexed and pits present. c-d. Melocactus ernestii Vaupel, black, shiny cochleariform seeds with rough surface, periclinal walls convexed, pits present. e-f. Pereskia aculeata Mill., black, shiny lenticular, rough surface, periclinal walls weakly convexed, pits absent, isodiametric cells present. g-h. Pereskia bahiensis Gürke, black, shiny lenticular seed, surface smooth, pits absent, isodiametric cells absent. i-j. Pilosocereus catingicola (Gürke) Byles \& Rowley, black, shiny cochleariform seeds, surface slightly rough, isodiametric cells weakly convexed, pits present. k-1. Stephanocereus leucostele (Gürke) A.Berger, brown, cochleariform, dull seeds, surface rough, periclinal cell walls totally convexed, pits absent. m-n. Tacinga werneri (Eggli) N.P.Taylor \& Stuppy, spheric, brownish, dull seed, surface smooth, pits absent. 
Material adicional examinado: BRASIL. BAHIA: Morro do Chapéu, Parque Estadual de Morro do ChapéuPEMC, Estrada nova do Prefeito, 12-X-2006, fl., E. Melo 4480 (HUEFS); Estrada Nova do Parque Estadual do Morro do Chapéu, 14-X-2006, fl., E. Melo 4554 (HUEFS); Abaíra, 22.IX.1992. W. Ganev 1167 (HUEFS).

\section{Tacinga werneri (Eggli) N.P.Taylor \& Stuppy}

Figuras 2 o, 3 m-n

\section{Nome popular: palmatória}

Cacto arbustivo ca. 1,5 m alt., verde escuro, segmentos do caule oval, achatados. Cladódios achatados, 57-189 ×54$149 \mathrm{~mm}$. Espinhos 10 por aréolas, 7-37 mm compr., alguns espinhos irregulares maiores, $25-46 \mathrm{~mm}$ compr. Flores diurnas, vermelhas, 22-29 × 6-12 mm, estames numerosos. Fruto ovoide a globoso, esverdeado e branco quando maduro, parede do ovário inteiramente rosada, 29-32 × 26-29 mm; sementes esféricas 2,5-3 × 2-3,4 mm, acastanhadas, opacas, superfície lisas, crateras ausentes.

Tacinga werneri apresenta flor avermelhada, 4 lobos estigmáticos, pericarpelo, 28 × $20 \mathrm{~mm}$ (Taylor \& Zappi 2004). T. werneri pode ser confundida com T. palmadora as quais se diferem basicamente pela flor e fruto, $T$. werneri apresenta flor de cor vermelha e frutos oval, esverdeado quando jovens e maduros branco com polpa rosada e $T$. palmadora apresenta flor de coloração alaranjada e frutos oval, de coloração esverdeada, avermelhado ou roxo e polpa esbranquiçada (Taylor \& Zappi 2004).

É uma espécie endêmica do Brasil, com ocorrência para áreas de Caatinga nos Estados da Bahia e Minas Gerais (Zappi \& Taylor 2020). No PNBN, T. werneri foi encontrada em área de Floresta Estacional Semidecidual e afloramento rochoso em uma pequena população com de cerca de 15 indivíduos, onde foi coletada com fruto no período agosto.

Material examinado: BRASIL. BAHIA: Parque Nacional de Boa Nova, Setor Leste, Fazenda Cotermaia, Região da Lagoa Danta, Lajedo do seu Zequinha, 14-VIII-2013, fr., L.Y.S. Aona et al. 3000 (HURB); Ibid., Setor Oeste, Fazenda Lagedão, 03-III-2013. L.Y.S. Aona et al. 2223 (HURB).

Material adicional examinado: BRASIL. BAHIA: Fazenda Canabrava, Lajedo, encosta da serra, Maracás, 19-VII-2012, fl, fr., E. Melo 11271 (HUEFS).

\section{Agradecimentos}

Os autores agradecem a W. Miliken, E. Lucas, E. Nic Lughadha, A. Haigh, N. Biggs (RBG, Kew), G. Costa, W.O. Fonseca (UFRB), J. Siqueira e J. Siqueira-Jr., pelo suporte durante o trabalho de campo; aos gestores O. Borges e J.S. Pereira (ICMBio), pela autorização concedida; à Mineradora Rio Tinto, pelo financiamento e suporte da parte de campo do presente estudo; ao $\mathrm{CNPq}$ pela autorização da parceria internacional entre UFRB e RBG, Kew (EXC 000003/2012-3). $\mathrm{DZ}$ recebe uma bolsa de produtividade do CNPq.

\section{Literatura citada}

Amorim, A.M., Jardim, J.G., Goldenberg, R. 2014. Physeterostemon gomesii (Melastomataceae): the fourth species of this endemic genus in Bahia, Brazil. Phytotaxa 175: 45-50.

Barthlott, W. \& Hunt, D. 2000. Seed-diversity in the Cactaceae. Subfam. Cactoideae. Vol. 5. Succulent Plant Research.

Birdlife Internacional. 2003. Feasibility Study for a Conservation Plan of Boa Nova Forests, Bahia, Bazil. Rélatorio técnico. Carla Morsello, consultora. Birdlife Internacional - Programa do Brasil. São Paulo.

Britton, N.L. \& Rose, J. N. 1919-1923. The Cactaceae, 1-4. Carnegie Institution, Washington, D.C. Vol. 1: 1919, vol. 2: 1920, vol. 3: 1922, vol. 4: 1923.

Carneiro, A.M., Farias-Singer, R., Ramos, R.A. \& Nilson, A.D. 2016. CACTOS do Rio Grande do Sul. Porto Alegre: Fundação Zoobotânica, do Rio Grande do Sul.

Gonzaga, D.R.; Zappi, D.C.; Furtado, S.G. \& Menini Neto L. 2014a. Cactaceae no Parque Estadual do Ibitipoca, Minas Gerais, Brasil. Boletim de Botânica da Universidade de São Paulo 32: 1-8.

Gonzaga, D.R., Zappi, D., Furtado, S.G. \& Menini Neto, L. 2014b. Cactaceae na Serra Negra, Minas Gerais, Brasil. Rodriguésia 65(2): pp. 443-453.

Gonzaga D.R., Menini Neto, L. \& Peixoto, A.L. 2017. Cactaceae no Parque Nacional do Itatiaia, Serra da Mantiqueira, Brasil. Rodriguésia 68(4): 1397-1410.

Hernández-Hernández, T., Brown, J.W., Schlumpberger, B.O., Eguiarte, L.E. \& Magallón, S. 2014. Beyond aridification: Multiple explanations for the elevated diversification of cacti in the New World Succulent Biome. New Phytol. 202: 1382-1397.

Hunt, D.R., Taylor, N.P. \& Charles, G. (eds.). 2006. The New Cactus Lexicon. Text volume. dh publications, Milborne Port.

Ministério do Meio Ambiente (MMA). 2006. Laudo Socioeconômico para a Criação de Novas Unidades de Conservação. Região de Boa Nova. Relatório da Equipe Técnico Científica para a Criação de UC's no Sul da Bahia. Márcio Ranauro, consultor. Ministério do Meio Ambiente - NAPMA. Brasília.

Meiado, M.V.; Aona, L.Y.S.; Nascimento, J.P.B.; Lima, A.T. \& Zappi, D.C. 2015. Cactaceae. In: Ana Paula do Nascimento Prata; Marta Cristina Vieira Farias; Myrna Friederichs Landim. (Org.). Flora de Sergipe. 1ed. Aracaju: Gráfica e Editora Triunfo, v. 2, pp. 115-142. 
Meido, M.V.; Lima, A.T.; Nascimento, J.P.B. \& Aona, L.Y.S. 2017. Avanços nos estudos sobre sementes e plântulas de cactos do Brasil. Gaia Scientia 11(4): 88-113.

Mendes, Z.R. \& Sebastiani, R. 2012. Cactaceae from Reserva Biológica do Alto da Serra de Paranapiacaba, Santo André, São Paulo State, Brazil. Hoehnea 39(3): 409-419.

Menezes, M.O.T.; Taylor, N.P. \& Loiola, M.I.B. 2013. Flora do Ceará, Brasil: Cactaceae. Rodriguésia.64: 757-774.

Nyffeler, R., \& Eggli, U. 2010. A farewell to dated ideas and concepts - Molecular phylogenetics and a revised suprageneric classification of the family Cactaceae. Schumannia 6: 109-149.

Ribeiro-Silva, S., Zappi, D.C., Taylor, N.P., Machado, M. (Orgs) 2011. Plano de Ação Nacional para Conservação das Cactáceas - Brasília: Instituto Chico Mendes de Conservação da Biodiversidade, ICMBIO. Série espécies ameaçadas 24.

Ritter, F. 1979. Kakteen in Südamerika, 1. F. Ritter Selbstverlag, Spangenberg.

Rizzini, C. T., Coimbra-Filho, A. \& Houaiss, F. E. 1988. Ecossistemas brasileiros. São Paulo: Editora Index.

Schumann, K.M. 1890. Cactaceae. In: Martius, C.F.P. von; Eichler, A.W. \& Urban, I. (eds.). Flora brasiliensis. Munchen, Wien, Leipzig. Vol. 4. pp. 185-322.

Sobral, M., Faria Jr., J.E.Q., Ibrahim, M.U., Lucas, E.J., Rigueira, D., Stadnik, A., Villaroel, D. 2015. Thirteen new Myrtaceae from Bahia, Brazil. Phytotaxa 224: 201-231.

Soller, A.; Soffiatti, P.; Calvente, A. \& Goldenberg, R. 2014. A família Cactaceae no estado do Paraná, Brasil. Rodriguésia 65: 201-219.

Taylor, N.P. \& Zappi, D.C. 2004. Cacti of Easten Brazil. Kew: Royal Botanic Gardens, Kew

Thiers, B. 2009 (continuously updated). Index Herbariorum: a global directory of public herbaria and associated staff. New York Botanical Garden's Virtual Herbarium. Available from http://sweetgum.nybg.org/science/ih (accessed 29-IV-2020).

Tuler, A.C., Peixoto, A.L. \& Proença, C.E.B. 2016. A new endangered species of Psidium (Myrtaceae, Myrteae) from Bahia, Brazil. Phytotaxa 288(2): 161-167.

Wilmot-Dear, C.M., Friis, Ib \& Monro, A.K. 2015. Pouzolzia saxophila sp. nov. (Urticaceae tribe Boehmerieae) from Bahia, Brazil. Nordic Journal of Botany 33: 354-357.
Vasconcelos, L.V.F., Gonzaga, D.R. \& Reis, R.C.C. 2019. Cactaceae Juss. no Parque Estadual da Serra da Tiririca, Rio de Janeiro, Brasil. Rodriguesia 70: 1-18.

Veloso, H.P.; Rangel, A.L.R. \& Lima, J.C.A. 1991. Classificação da Vegetação Brasileira, Adaptada a um Sistema Universal. Rio De Janeiro IBGE, Departamento de Recursos, Naturais e Estudos Ambientais, pp. 63-73.

Zappi, D. 1994. Pilosocereus (Cactaceae) The genus in Brazil. The Botanic Garden-Kew, Richmond.

Zappi, D., Aona, L.Y.S. \& Taylor, N. 2007. Cactaceae In: Melhem, T.S., Wanderley, M.G.L., Martins, S.E., JungMendaçolli, S.L., Shepherd, G.J., Kirizawa, M. (eds.) Flora Fanerogâmica do Estado de São Paulo. Instituto de Botânica, São Paulo 5: 163-194.

Zappi, D.; Ribeiro-Sila, S.; Aona, L.Y.S.; Taylor, N. 2011. Parte I: Aspectos Ecológicos e Biologia Reprodutiva. In: Silva, R. S.; Zappi, D.; Taylor, N.; Machado, M. Plano de ação nacional para a conservação das Cactáceas. Brasília-DF: Instituto Chico Mendes de Conservação e Biodiversidade, pp. 36-41.

Zappi, D.; Taylor, N.; Machado, M. \& Santos, M.R. 2011. Parte I: Ameaças. In: Silva, R. S.; Zappi, D.; Taylor, N.; Machado, M. Plano de ação nacional para a conservação das Cactaceae. Brasília-DF: Instituto Chico Mendes de Conservação e Biodiversidade, pp. 53-55.

Zappi, D.; Taylor, N. \& Santos, M.R. 2011. Parte I: Conservação das Cactaceae do Brasil. In: Silva, R. S.; Zappi, D.; Taylor, N.; Machado, M. Plano de ação nacional para a conservação das Cactaceae. Brasília-DF: Instituto Chico Mendes de Conservação e Biodiversidade, pp. 27-28.

Zappi, D.C.; Taylor, N.P., Damasceno Jr, G.A., Pott, V.J. \& Machado, M.C. 2018. Check-list das Cactaceae do estado do Mato Grosso do Sul, Brasil. Heringia 73: 169-173.

Zappi, D. \& Taylor, N. 2008. Diversidade e endemismo das Cactaceae em Cadeia do Espinhaço. Megadivesidade 4(1-2): 111-116.

Zappi, D.C. \& Taylor, N.P. 2017. Flora das cangas da Serra dos Carajás, Pará, Brasil: Cactaceae. Rodriguésia 68(3): 925-929.

Zappi, D. \& Taylor, N. 2020. Cactaceae in Flora do Brasil 2020 em construção. Jardim Botânico do Rio de Janeiro. Disponível em <http://floradobrasil.jbrj.gov.br/reflora/ floradobrasil/FB1622> (acesso em 1-V-2020). 